Dzheimison, F. (2019) Postmodernizm, ili Kul'turnaia logika pozdnego kapitalizma / transl. from Engl. by D. Kralechkin; ed. by A. Oleinikov. Moscow, Izd-vo Instituta Gaidara. 808 p. (In Russ.).

Kushnareva, I. (2013) Kak nas priuchili k serialam. Logos, vol. 23, no. 3, pp. 9-20. (In Russ.).

Pavlov, A. V. (2018) Obrazy sovremennosti v XXI veke: metamodernizm. Logos, vol. 28, no. 6, pp. 1-19. (In Russ.).

Safronov, E. E. (2019) Populiarnaia kul'tura kak religiia. Retsenziia na: Posssamai, A. (ed.) (2012) Handbook of Hyper-Real Religions. Leiden, London : Brill. Gosudarstvo, religiia, tserkov'v Rossii $i$ za rubezhom, no. 3(37), pp. 277-283. DOI: 10.22394/2073-7203-2019-37-3-277-283 (In Russ.).

Fedotova, V. G. (2018) Dva printsipa postroeniia sotsial'noi filosofii. Filosofskie nauki, no. 6, pp. 128-131. (In Russ.).

Chubarov, I. and Sechenova, E. (2019) Levaia kritika v epokhu platformennogo kapitalizma. Logos, vol. 29, no. 6, pp. 275-308. (In Russ.).

Danowski, D., de Castro, V. E. (2017) The Ends of the World. Cambridge, Polity Press. 186 p.

Occhi, D. J. (2012) Performance, and Message: Comparing Japanese Kyara with their Anthropomoprhic Forebears. Asian Etbnology, vol. 71, no. 1, pp. 109-132.

Santili, P. (2007) Culture, Evil, and Horror. Economics and Sociology, vol. 66, no. 1, pp. 173-194.

Shigemi, I. (1999) Miyazaki Hayao's Epic Comic Series: "Nausicaä in the Valley of the Wind": An Attempt of Interpretation. Japan Review, no. 11, pp. 113-127.

Vermeulen, T., van den Akker, R. (2010) Notes on Metamodernism. Journal of Aesthetics \& Culture, vol. 2, pp. 1-14.

White, M. and Irwin, W. (eds.) (2010) Iron Man and Pbilosopby : Facing the Stark Reality. Hoboken, Wiley. 288 p.

Submission date: 10.01.2020.

Афанасов Николай Борисович - младший научный сотрудник сектора социальной философии Института философии РАН. Адрес: 109240, Россия, г. Москва, ул. Гончарная, А. 12, стр. 1. Тел.: +7 (495) 697-98-93. Эл. адpec: n.afanasov@gmail.com

Afanasov Nikolay Borisovich, Junior Research Fellow, Sector of Social Philosophy, RAS Institute of Philosophy. Postal address: 12, Bldg. 1, Goncharnaya St., Moscow, Russian Federation, 109240. Tel.: + 7 (495) 697-98-93. E-mail: n.afanasov@gmail.com

DOI: $10.17805 /$ zpu.2020.2.20

\title{
Две концепции справедливости: спекулятивный материализм и нефилософия
}

\author{
A. В. МОРОЗОВ \\ ИНСТИТУТ ФИЛОСОФИИ РАН
}

Статья посвящена разбору и сопоставлению двух концепций утопической справедливости, представленных французскими философами Квентином Мейясу и Франсуа Ларюэлем. По гипотезе автора, проект «нефилософской этики» Ларюэля, развернутый им в книге «Общая теория жертв», является непосредственным ответом на тезисы, которые были изложены Мейясу в докторской диссертации и ряде последующих статей. И спекулятивный материализм Мейясу, и нефилософия Ларюэля вместе с тем содержательно пересекаются в нескольких отношениях, которые не ограничены полем социальной философии и метафизической этики. 
Кратко рассматриваются и сопоставляются общие философские проекты и стратегии Мейясу и Ларюэля. Обнаруживается ряд значимых параллелей. Разбираются спекулятивно-материалистическая и нефилософская концепции справедливости, вытекающие из описанных в первом разделе общих проектов.

Автор приходит к выводу, что “Общая теория жертв» Ларюэля является поэтапным развенчиванием проекта Мейясу и что выдвинутая Ларюэлем концепция справедливости является более демократической по характеру.

Ключевые слова: спекулятивный материализм; нефилософия; социальная философия; метафизическая этика; справедливость; утопия; мессианизм; Квентин Мейясу; Франсуа Ларюэль

\section{ВВЕАЕНИЕ}

$\mathrm{B}$ европейской философии в последние годы все чаще стали вновь обращаться к теме справедливости, особенно в мессианистском ключе.

В настоящей статье я хотел бы сопоставить две новые концепции утопической справедливости, выдвинутые французскими философами Квентином Мейясу (р. 1967) и Франсуа Аарюэлем (р. 1937). При этом я предполагаю, что, пускай Аарюэль ни разу не упоминает Мейясу и его проект, его книга 2012 г. (Laruelle, 2015) выстраивается как ответ на тезисы, изложенные младшим коллегой в докторской диссертации (англ. пер. фрагментов: Meillassoux, 2011).

Аанное обстоятельство пока не было отмечено никем из отечественных и зарубежных исследователей, и далее я приведу доводы в пользу своего предположения. Необходимо отметить, что Аарюэль редко прибегает к прямым цитатам и открытым упоминаниям других философов, даже когда ведет полемику, и поэтому восстановление контекста - задача далеко не тривиальная.

Все положения, выдвинутые указанными двумя философами в поле, которое условно можно было бы обозначить как пересечение социальной философии и метафизической этики (в традиции Э. Аевинаса и др.), опираются на их более общие проекты - спекулятивный материализм и нефилософию соответственно. Поэтому вначале я вкратце обозначу их содержание. Именно сходство проектов во многом определяет тон заочной полемики. Аалее я перейду непосредственно к разбору концепций справедливости Мейясу и Аарюэля.

\section{НЕАОСТАТОЧНОСТЬ ОСНОВАНИЯ}

Проект Мейясу, называемый им «спекулятивным материализмом», состоит в отказе от трансцендентальной дедукции И. Канта. В поисках нетрансцендентального основания постоянства физических законов мира Мейясу приходит к выводу, что у законов природы не имеется основания, которое можно было бы назвать надежным и крепким, иными словами, достаточным - но это и позволяет ему заключить, что их постоянство может гарантироваться лишь в силу принципиальной не-необходимости, а точнее - их необходимой контингентности (Мейясу, 2015: 52-54, 88-89).

О любом сущем, которое мы с вами познаем, можно сказать, что оно либо таково, как оно есть, либо может стать другим, либо может перестать быть, и это и есть единственное четкое и подлинное содержание познания. Причем это «таково» вещи Мейясу рассматривает как ее первичные качества, которые поддаются математизации: он восстанавливает различие первичных и вторичных качеств, и поэтому в конечном счете онтология оказывается математикой, как у его учителя А. Бадью (Бадью, 2012). Но почему же постоянство законов природы так постоянно, почему оно не может сме- 
ниться прямо в следующий момент, ведь если никакого основания у них нет, оно представляется совершенно невероятным?

Аело в том, что рассуждения о вероятности тут вовсе не применимы. Обращаясь к теории множеств в духе Бадью, Мейясу говорит о том, что мира, понятого как множество всех множеств, т. е. как множества всех возможных множеств случаев, событий и происшествий в мире, не существует - всегда можно построить множество всех подмножеств данного множества, которое будет больше, чем это множество, и это также можно проделать и с миром, а затем с множеством всех подмножеств мира и т. А. и т. п. до бесконечности (Мейясу, 2015: 118, 154-155).

Мейясу отвергает принцип достаточного основания, заменяя его недостаточным основанием (необходимой контингентностью), и отвергает существование мира как некой тотальности, вследствие чего он также отвергает редукцию мира (коль скоро его не существует) к набору трансцендентальных условий, предоставляемых некоторой субъективной инстанцией. Можно было бы сказать, что то, что, по Мейясу, дано субъекту, дано субъекту без данности, т. е. без опосредующей структуры или механизма данности, - оно просто дано.

В свою очередь, проект $\Lambda$ арюэля, который он называет нефилософией, или нестандартной философией, тоже опирается на отвержение принципа достаточного основания и спекулятивный отказ от мира, вот только оформляет он их совершенно иначе (Марюэль, 2013). Аарюэль также исходил из своеобразной реалистической позиции и задолго до Мейясу, который дал ей имя, желал отринуть корреляционистскую установку философии ${ }^{1}$, запирающей реальное в круговорот с мыслью, в отношения их взаимной детерминации, чтобы установить между мыслью и реальным новое отношение или, скорее, неотношение.

Реальное, по Аарюэлю, отлучено от мысли, закрыто для нее, так что мысль не может вступить с ним в отношения репрезентации. Иначе говоря, мы не можем мыслить Реальное как таковое, мы не можем мыслить о нем, однако мы можем мыслить исходя из него. Как это осуществляется? Ход рассуждений Аарюэля следующий: Реальное $^{2}$ всегда нам уже дано, но без данности, или дарения; данное-без-данности же описывается аксиоматическим образом с помощью наиболее «обедненного» формализма (Марюэль, 2013: 11-12).

Но если для Мейясу доступ к реальности давал бедный - в смысле его референциальной бессодержательности (Мейясу, 2017: 77-78) - формализм математики, то в случае Аарюэля речь идет о формализме, получаемом в итоге очистки от содержания некоторой трансцендентальной философии ${ }^{3}$. Вместо математических пустых знаков, открывающих нам «в-себе» реальности, мы имеем дело с «радикальными» понятиями, которые «аффицированы имманентностью» и позволяют нам пусть не познать и не помыслить Реальное, но аксиоматически его задать и делать на основании аксиом те или иные заключения, как пишет последовательница Аарюэля К. Колозова (Kolozova, 2009: Электронный ресурс).

Что касается принципа достаточного основания, Марюэль отвергает его в виде «принципа достаточной философии» - претензии философии как формы идеального на такое определение Реального, которое бы его конституировало. Стандартная философия в акте Решения устанавливает Реальное и образует мысль-мир как общую форму всех явлений (Марюэль, 2013: 18-19), своего рода «множество всех множеств», которое подвергал критике Мейясу, т. е. всеобщую опосредующую структуру данности с четкими «законами». Аарюэль же указывает на необходимый, однако ни в коей 
мере не достаточный характер Реального, чьи эффекты в виде разных (и определяемых в конечном счете именно им) Решений и их «законов» контингентны (Морозов, 2019: 229-231).

\section{НЕРОЖАЕННЫЙ БОГ И ОБЫАЕННЫЕ МЕССИИ}

Книга Мейясу «После конечности» (2006) (рус. пер.: Мейясу, 2015) представляла собой переработку части его диссертации «Божественное несуществование» (1997) (англ. пер. фрагментов: Meillassoux, 2011). В рамках диссертации онтологический проект, изложенный им в книге как самостоятельный, предваряет этический проект Мейясу и оказывается ему подчиненным.

Казалось бы, если Мейясу не признает абсолютной необходимости, кроме необходимости контингентности, в его философии не должно быть места Богу. И все же оно обнаруживается - вот только как пустующее. Аело в том, что, как полагает Мейясу, в своем осмыслении жертв - насильственной кончины людей и смерти в целом - мы всегда наталкиваемся на дилемму атеизма и религии. Скорбь невозможна, если мы не можем надеяться на жизнь после смерти и дальнейшее воссоединение с умершими в мире ином, с точки зрения человека религиозного; с точки зрения же атеиста, существование Бога, якобы обещающее жизнь после смерти, препятствует такой надежде, ведь лишь злой Бог мог допустить такие жертвы. Однако спекулятивно доступен и третий вариант, допускающий как воссоединение с мертвыми, так и несуществование Бога, и состоит он в признании Бога еще не существующим (Мейясу, 2013: 74-75).

В условной «космологии» Мейясу имеется три больших множества, охватывающих более мелкие, - Мир материи, Мир жизни и Мир мысли, каждый из которых несводим к предыдущему и возник без причины, ex nibilo (Meillassoux, 2011: 190). Вышеописанный спекулятивный вариант для Мейясу указывает на возможность подобного возникновения «из ничего» четвертого Мира - Мира справедливости, ознаменованного всеобщим воскресением людей и отменяющего смерть. Несмотря на то что Мейясу ранее отказал нам в каузальной действенности - коль скоро достаточного основания быть не может, - он оборачивает свой же тезис, говоря о том, что мы имеем шанс способствовать приходу Мира справедливости: будучи каузально независимым от нас, он некаузально зависит от нашей надежды и исполняемых во имя ее действий. Тем самым все человечество становится утробой для Бога, которого, как предполагает Мейясу, возвестит человеческий посредник, «подобный Христу», всеблагой, всезнающий, всемогущий, способный отказаться от всезнания и всемогущества - и отказывающийся от них после того, как воскресит мертвых (Meillassoux, 2011: 216, 224-225).

\арюэль в своем этическом проекте тоже ставит во главу угла жертв, больше того он полагает Жертву в качестве одного из имен Реального. Но дело не в том, чтобы рассуждать о жертвах, а в том, чтобы рассуждать исходя из них. Философы вечно переключаются с жертв на что-то другое, например на насилие или власть, и их размышления замыкаются в круге жертв и их гонителей, который должен так или иначе разомкнуть в лице философа ангажированный интеллектуал. Причем зачастую больше всего внимания уделяется именно гонителям, преступникам и т. п., а не жертвам, изза чего Аарюэль уподобляет всю философию как по форме, так и по содержанию миметическому соперничеству, описанному Р. Жираром (Жирар, 2019): с другим философом; с гонителем; наконец, с самой жертвой, которую этот интеллектуал, если и замечает, склонен путать с ее медиатизированными образами (Laruelle, 2015: 29, 34). 
Мейясу выделил четыре возможных связи человека с Богом. Аве из них вполне банальны: «верю, потому что он есть» и «не верю, потому что его нет». Но имеются и две причудливые: «не верю, потому что он есть» и «верю, потому что его нет» - причем сам Мейясу как наиболее, по его мнению, радикальную избирает последнюю (Meillassoux, 2011: 237-238). Марюэль, явно откликаясь на выкладки Мейясу, также рассматривает эти связи, однако выбирает для себя третью: «..банальный отказ верить в Бога противоречив и удовлетворяет малодумных, но отказ верить во всеблагого Бога - вот истинный бунт... ибо Бог всегда таится в засаде, готовя свое возвращение через любое отрицание, что сотворили из его существования, пусть даже материалистическое» (Laruelle, 2015: 21).

Спекулятивно-материалистический Бог восстанавливает иерархию и круг зла, выставляя себя - и/или своего христоподобного посредника - в роли спасителя от великого гонителя слабых, смерти; отделяя наиболее слабых - мертвых - от менее слабых, живых, и поручая им работу по вынашиванию его возвращения; и лишая всех слабых, будь то мертвых или живых людей, всякой силы по сравнению с собой и своим посредником. С позиции нестандартной этики, однако, Жертва, будь то эмпирически живая или мертвая, всегда мертва в Реальном, и потому разницы между живыми скорбящими и мертвыми жертвами $b$ конечном счете нет. Но у Жертвы остается «слабая сила» указать на своего гонителя, тем самым осуществив «восстание из смерти», смыкающее воскрешение (ressurection) с бунтом (insurrection). Всякий человек, таким образом, становится христоподобным медиатором между Миром, в котором мы живем и умираем, и утопической Вселенной будущего - «обыденным мессией», который опирается не на скорбь и жалость к умершим, но на сострадание к родовому «телу славы» Человека в муках и привносит в наш Мир из этого будущего перемены (Laruelle, 2015: 45-49, 78-82, 121).

\section{ЗАКАЮЧЕНИЕ}

«Общая теория жертв» $а$ арюэля, таким образом, выстраивается как поэтапное опровержение тезисов диссертации Мейясу. Марюэль отвергает идеалистическое решение Мейясу - постулат об акаузальном воздействии идеального (работы скорби и надежды) на Реальное - в пользу позиции, исходящей из человека как Жертвы или Реального, и сострадания к нему, которое открывает нам доступ к односторонней детерминации идеального мира явлений, мира жизни и смерти Реальным и к более демократическому отправлению справедливости.

\section{ПРИМЕЧАНИЯ}

1 Эта установка, господствующая в философии после Канта, описывается Мейясу так: «Под “корреляцией” мы понимаем идею, согласно которой мы можем иметь доступ только к корреляции между мышлением и бытием, но никогда к чему-то одному из них в отдельности. Мы будем называть “корреляционизмом" любое направление мысли, которое утверждает непреодолимый характер корреляции, понятой таким образом» (Мейясу, 2015: 11). О совпадении «корреляционизма» и «философии» в понимании Аарюэля писал Н. Срничек (Srnicek, 2010: Электронный ресурс).

2 «Реальное», как и ряд других терминов (Решение, Мир, Вселенная, Человек, Жертва и т. А.), Аарюэль пишет с заглавной буквы, тем самым подчеркивая, что они выступают в его системе абстрактными операциональными понятиями.

${ }^{3}$ Как отмечает Р. Брассье, с точки зрения Аарюэля, всякая философия, в отличие от его нефилософии, опирается на тот или иной вариант трансцендентальной дедукции, как до Канта, так и после, как в Европе, так и в других уголках мира (Brassier, 2007: 122-126). 


\section{СПИСОК АИТЕРАТУРЫ}

Бадью, А. (2012) Манифест философии. СПб. : Machina. 192 с.

Жирар, Р. (2019) Вещи, сокрытые от создания мира. М. : ББИ. 532 с.

Аарюэль, Ф. (2013) Словарь нефилософии // Синий Аиван. № 18. С. 7-30.

Мейясу, К. (2013) Аилемма призрака // Аогос. №93. С. 70-80.

Мейясу, К. (2015) После конечности. Екатеринбург ; М. : Кабинетный ученый. 194 с.

Мейясу, К. (2017) Итерация, реитерация, повторение. Спекулятивный анализ знака, лишенного смысла // Транслит. № 19. С. 77-85.

Морозов, А. (2019) Навигация по акселерационизму: от некапитализма к посткапитализму через платформы // Galactica Media: Journal of Media Studies. Tом 1. №2. C. 226-242. DOI: 10.24411/2658-7734-2019-10020.

Brassier, R. (2007) Nihil Unbound: Enlightenment and Extinction. New York : Palgrave Macmillan. 275 p.

Kolozova, K. (2009) Thinking the Political by Way of "Radical Concepts" [Электронный peсурс] // International Journal of Žižek Studies. Vol. 3. №1. URL: http://zizekstudies.org/index. $\mathrm{php} / \mathrm{IJZS} /$ article/view/135/135 (дата обращения: 17.03.2020).

Laruelle, F. (2015) General Theory of Victims. Malden, MA : Polity Press. 184 p.

Meillassoux, Q. (2011) Excerpts from L'Inexistence divine // Harman, G. Quentin Meillassoux: Philosophy in the Making. Edinburgh : Edinburgh University Press. 240 p. P. 175-218.

Srnicek, N. (2010) François Laruelle, the One and the Non-Philosophical Tradition [Электронный pecypc] // King's College London. URL: http://kclpure.kcl.ac.uk/portal/en/publications/francoislaruelle-the-one-and-the-nonphilosophical-tradition(edf30549-9f4e-4645-a176-a0e4e19b6d9d).html (дата обращения: 17.03.2020).

Аата поступления: 18.03 .2020 2.

TWO CONCEPTIONS OF JUSTICE:

SPECULATIVE MATERIALISM AND NON-PHILOSOPHY

\section{A. V. MOROZOV}

RAS INSTITUTE OF PHILOSOPHY

The article is devoted to the analysis and comparison of two concepts of utopian justice presented by French philosophers Quentin Meillassoux and François Laruelle. According to the author's hypothesis, Laruelle's project of "non-philosophical ethics", which he developed in "General Theory of Victims", is a direct response to the theses that were presented in Meillassoux's dissertation and several subsequent articles. Both Meillassoux's speculative materialism and Laruelle's non-philosophy intersect in several aspects which, however, are not limited to the field of social philosophy and metaphysical ethics.

The general philosophical projects and strategies of Meillassoux and Laruelle are briefly examined and compared. There are a number of significant parallels. The author analyses the speculative materialist and non-philosophical conceptions of justice arising from the general projects described in the first section.

The author comes to the conclusion that Laruelle's "General Theory of Victims" is a step-by-step refutation of Meillassoux's project and that the conception of justice provided by Laruelle is more democratic in its character.

Keywords: speculative materialism; non-philosophy; social philosophy; metaphysical ethics; justice; utopia; messianism; victims; Quentin Meillassoux; François Laruelle

\section{REFERENCES}

Badiou, A. (2012) Manifest filosofii. St. Petersburg, Machina. 192 p. (In Russ.)

Girard, R. (2019) Veshchi, sokrytye ot sozdaniia mira. Moscow, BBI. 532 p. (In Russ.)

Laruelle, F. (2013) Slovar' nefilosofii. Sinii Divan, no. 18, pp. 7-30. (In Russ.)

Meillassoux, Q. (2013) Dilemma prizraka. Logos, no. 93, pp. 70-80. (In Russ.) 

Russ.)

Meillassoux, Q. (2015) Posle konechnosti. Ekaterinburg, Moscow, Kabinetnyi uchenyi. 194 p. (In

Meillassoux, Q. (2017) Iteratsiia, reiteratsiia, povtorenie. Spekuliativnyi analiz znaka, lishennogo smysla. Translit, no. 19, pp. 77-85. (In Russ.)

Morozov, A. (2019) Navigatsiia po akseleratsionizmu: ot nekapitalizma k postkapitalizmu cherez platformy. Galactica Media: Journal of Media Studies, vol. 1, no. 2, pp. 226-242. DOI: 10.24411/ 2658-7734-2019-10020. (In Russ.)

Brassier, R. (2007) Nibil Unbound: Enlightenment and Extinction. New York, Palgrave Macmillan. 275 p.

Kolozova, K. (2009) Thinking the Political by Way of "Radical Concepts". International Journal of Žižek Studies, vol. 3, no. 1 [online] Available at: http://zizekstudies.org/index.php/IJZS/article/ view/135/135 (accessed: 17.03.2020).

Laruelle, F. (2015) General Theory of Victims. Malden, MA, Polity Press. 184 p.

Meillassoux, Q. (2011) Excerpts from L'Inexistence divine. In: Harman, G. Quentin Meillassoux: Philosopby in the Making. Edinburgh, Edinburgh University Press. 240 p. Pp. 175-218.

Srnicek, N. (2010) François Laruelle, the One and the Non-Philosophical Tradition. King's College London [online] Available at: http://kclpure.kcl.ac.uk/portal/en/publications/francoislaruelle-the-one-and-the-nonphilosophical-tradition(edf30549-9f4e-4645-a176-a0e4e19b6d9d).html (accessed: 17.03.2020).

Submission date: 18.03 .2020$.

Морозов Артем Владимирович - младший научный сотрудник сектора социальной философии Института философии РАН. Адрес: 109240, Россия, г. Москва, ул. Гончарная, А. 12, стр. 1. Тел.: +7 (495) 697-98-93. Эл. аapec: morozov.socphil@yandex.ru

Morozov Artem Vladimirovich, Junior Research Fellow, Sector of Social Philosophy, RAS Institute of Philosophy. Postal address: 12, Bldg. 1, Goncharnaya St., Moscow, Russian Federation, 109240. Tel.: +7 (495) 697-98-93. E-mail: morozov.socphil@yandex.ru

DOI: $10.17805 / z p u .2020 .2 .21$

\title{
Социологическая концептуализация электронных денег: сложности и перспективы
}

\author{
E. C. МАКАРОВ
}

РОССИЙСКИЙ ЭКОНОМИЧЕСКИЙ УНИВЕРСИТЕТ ИМЕНИ Г. В. ПЛЕХАНОВА

В статье представлена концептуализация электронных денег в рамках различных социологических оптик. Электронные деньги рассматриваются как множественный феномен, встроенный в социальную жизнь как на уровне смыслов, так и на повседневном уровне.

На основе анализа феномена электронных денег через призму двух концептуальных оптик - теории множественных денег В. Зелизер и материальной социологии повседневности В. Вахштайна - делаются выводы о возможностях совместимости двух концепций и некоторых их принципиальных различиях.

Ключевые слова: электронные деньги; социология денег; экономическая социология; множественные деньги; социология повседневности 